\title{
The Truth of Eating Different Fruits, Herbs, Honey etc. as Good Treatments for all Diabetes Types and for Hypertension in Different Societies
}

Al-Darraji AHK* and Abd-Al-Saheeb YS

Department of Chemistry, College of Science, Missan University, Iraq

\begin{abstract}
There are different fruits, vegetables, herbs, honey etc. are used in different countries as a good treatments for different types of diabetes and for hypertension diseases. These countries used these natural products without knowing why they use them? and how they reduce glucose concentration in the blood? and how they reduce blood's pressure?

In this research concentrations of potassium and sodium were measured in honey samples that come from different sources and they measured for widely using and so known plants "Cinnamomum verum". These natural products are used as a good treatments for diabetes and hypertension and this why this research has choosed them.
\end{abstract}

The fact of this research it discuss just scientific facts just only them for illustrating the important treatment for diabetes and hypertension diseases which is a appropriate amount from both ions potassium and sodium ions.

Keywords: Diabetes; Hypertension; Potassium; Sodium

\section{Introduction}

Diabetes is chronic polyuria resulting from various metabolic disorders. In most cases, the polyuria results from a high concentration of glucose in the renal tubule. Diabetes mellitus result primarily from inadequate secretion of insulin or the inability of tissues to respond to insulin. Insulin-dependent diabetes mellitus (IDDM), also called type 1 diabetes mellitus, affects approximately $3 \%$ of people with diabetes mellitus and results from diminished insulin secretion. Noninsulin-dependent diabetes mellitus (NIDDM), also called type 2 diabetes mellitus, results from the inability of tissues to respond to insulin. NIDDM usually develops in people older than 40-45 years of age, although the age of onset varies considerably. A strong genetic component exists in the disease, but its actual cause is known. NIDDM is more common than IDDM. Approximately $97 \%$ of people who have diabetes mellitus have NIDDM [1].

In addition, blood's pressure is a measuring of the force blood exerts against blood vessel walls. Two pressures are recorded: (1) Systolic pressure is the peak arterial BP attained during ventricular systole. (2) Diastolic pressure is the minimum arterial BP between heartbeats. For a healthy person, arterial BP is written as a ratio of systolic over diastolic pressure: 120/75 [1].

There is a relation between diabetes and hypertension diseases about $80 \%$ of diabetic patients have a hypertension, patient with diabetes type 2 is so common it has a hypertension [1].

\section{Experimental Part}

Four samples were taken as examples for different fruits, vegetable, herbs and honey that are used before long time ago by so many people here because they act as good treatments for diabetes and hypertension. Three samples were honey $(\mathrm{H} 1, \mathrm{H} 2$ and $\mathrm{H} 3)$ that produce from different sources a $1 \mathrm{~mL}$ of each one has dissolved in $5 \mathrm{~mL}$ of distilled water. By using flame spectrophotometer in analytical chemistry laboratory, concentrations of potassium and sodium ions were calculated in these samples. As same as this technique concentration of potassium and sodium ions were calculated in the last sample "C. verum". 1 gram of this plant in $5 \mathrm{~mL}$ distilled water.

\section{Results and Discussion}

Results of this research are in following Table 1:

It is well known that most fruits and herbs contain variety concentrations from potassium and sodium ions. People over the world choose and use only those natural products that contain high concentrations from these ions as it is shown in above results Figure 1. Honey's sources are not important for this research due to that people use all of them as a good treatment.

As it is mentioned before that this research discusses and deal with just facts and only facts that are:

1. Glucose molecules are so important for human's energy, after each meal concentration of these molecules in blood should be at higher levels than before then after few hours it decrease stepwise to low levels, human's cells absorb these molecules by assisting of insulin molecules [1,5-7].

2. Insulin hormone are so important in absorbing process of

\begin{tabular}{|c|c|c|c|}
\hline $\mathbf{N}$ & Samples & Potassium conc. mg/L & $\begin{array}{c}\text { Sodium conc. } \\
\mathbf{m g} / \mathbf{L}\end{array}$ \\
\hline 1 & $\mathrm{H}_{1}$ & 54.8746 & 11.87943 \\
\hline 2 & $\mathrm{H}_{2}$ & 54.30333 & 15.73286 \\
\hline 3 & $\mathrm{H}_{3}$ & 45.2574 & 12.56501 \\
\hline 4 & Cinnamomum verum & 27.52 & 20.387079 \\
\hline
\end{tabular}

Table 1: Concentration of potassium and sodium ions.

*Corresponding author: Al-Darraji AHK, Department of Chemistry, College of Science, Missan University, Iraq, Tel: 52293-64436; E-mail: alaa_h_k@yahoo.com

Received: December 03, 2018; Accepted: December 17, 2018; Published December 21, 2018

Citation: Al-Darraji AHK, Abd-Al-Saheeb YS (2018) The Truth of Eating Different Fruits, Herbs, Honey etc. as Good Treatments for all Diabetes Types and for Hypertension in Different Societies. Biochem Anal Biochem 7: 369. doi: 10.4172/2161-1009.1000369

Copyright: ( 2018 Al-Darraji AHK, et al. This is an open-access article distributed under the terms of the Creative Commons Attribution License, which permits unrestricted use, distribution, and reproduction in any medium, provided the original author and source are credited. 


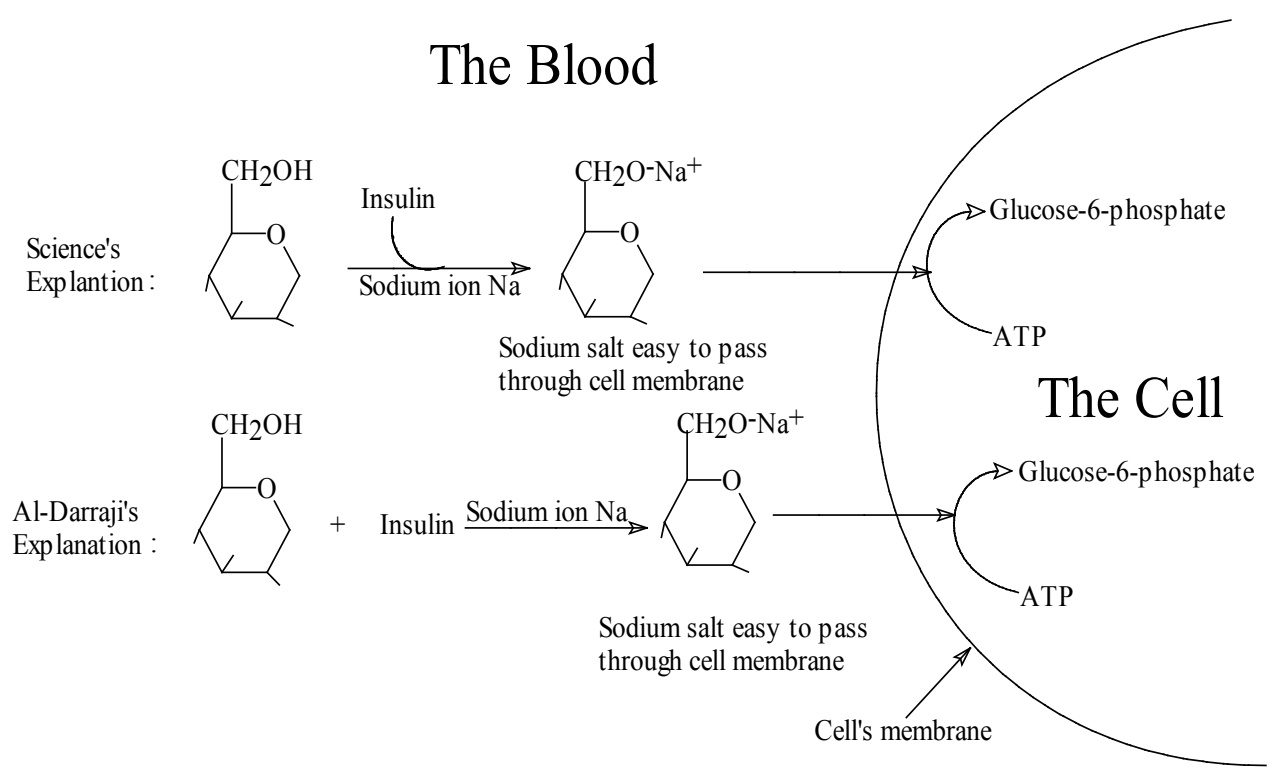

Figure 1: Show the differences between Al-Darraji's explanation [1] and the science's explanation [2-7].

glucose by human's cells, this fact is well known in case of diabetes patients type 1 when $\beta$-cells are destroyed unable to release these molecules [1,5-7].

3. Insulin should interact with glucose molecules in the blood does not with cell's membrane because; Firstly if insulin react with cell's membrane then the resulting changes should be continue for long time leading absorb more glucose molecules resulting there is no need for another insulin. This does not happen in the human's body, releasing of insulin is continues in response to glucose's concentration in the blood. Secondly, it is impossible for insulin molecules to react with all cells of human's body because they cannot reach them, they reach only cells that they are in contact with the blood. Thirdly, if insulin react with cell's membrane then it must make a suitable hole making glucose able to penetrate through, these holes must let other different molecules like glucose or others enter body's cells resulting high densities leading to destroy human's cells, this does not happen in human's body. Fourthly, chemical structures of insulin and cell's membrane are well studied no way to interact each other. Lastly, references and different studies over the world do not mention anything about any interaction of insulin with cell's membrane [1-7].

4. After each meal glucose concentration in the blood should rise to higher levels than before, then it decreases systematically due to insulin. This fact is well studied that insulin responsible for decreasing of glucose concentration in the blood [1].

5. Glucose stay in the blood do not entering body's cells unless insulin do a certain action on it make it able to pass through cell's membrane and it is important to mention a fact that chemical structure of glucose do not change before and after its passing through cell's membrane [1-7].

6. Chemical structure of glucose $\left(\mathrm{C}_{6} \mathrm{H}_{12} \mathrm{O}_{6}\right)$ and insulin (51 different amino acids) stay same before and after passing process and this have one explanation only according to chemical structures of these molecules [1].
7. For knowing diabetes treatment it should follow glucose path through body's cells because reactions of glucose with insulin are continue in the blood due to exist of both molecules in the blood continually. This reaction is the reason why glucose pass through cell's membrane (Table 1).

Above facts are very well studied and they are simple facts for glucose molecules paths in human's body but there are two important facts more important than above facts should lead this research to its target which are; Glucose molecules enter body's cells with sodium ions $[1,5,7]$ and the second that potassium ions have a major role in the glucose path through cell's membrane and also they are important for diabetes and hypertension treatments [1-4]. These facts are well known but unfortunately they do not explain what is the connection type (bond kind) between glucose and sodium ion when the entering through cell's membrane! This connection is so important for understanding diabetes treatment because these chemicals an atom with molecules cannot pass through cell's membrane together unless they bind each other by specific known bind.

Glucose-sodium binding must happen because glucose as it is in the blood do not have the ability to pass through cell's membrane and also insulin must do something on it for making it able to pass through cell's membrane. These are facts that glucose cannot pass through cell's membrane as it is and insulin must do something on this molecule.

It is a fact that there are two explanations for glucose path through cell's membrane but both of them have same product "glucose-sodium molecule". These explanation are what science find until now about glucose path [5,6] and what Al-Darraji found in his explanation [1] Following scheme will show depending on chemical structures what the differences between these two explanations:

It is so obvious that both explanations have same products which are sodium-glucose molecule that is as a salt. Addition fact is that this salt should have good ability to pass through cell's membrane. Sodiumglucose molecules after passing through cell's membrane it reacts with ATP (adenosine Triphosphate) to produce glucose-6-phosphate and sodium ions should stay inside the cell but this should depend on them 
concentrations outside-inside the cell. Then other steps should occur until glucose convert to $\mathrm{CO}_{2}$ molecules.

Novel studies [1-4] showed that potassium ions are so important for diabetes treatment and their low serum's levels should increase risk of diabetes disease [2-4] even in all diabetes types [1]. Nevertheless for this research's target or for this research calculations potassium's role in glucose path should be neglected in the flowing statements.

Sciences of human's body are limited by its facts as same as different chemical reactions! These reactions have known starting material and they know them products but how these products formed "reaction's mechanism" is unknown. Therefore, in case of glucose path from the blood (Glucose-sodium molecule) to cell's cytoplasm (glucose-6phosphate) is the important path for finding or for identifying diabetes' causes and its treatments. In this status three cases should be noticed.

1. Chemical structure of glucose $\left(\mathrm{C}_{6} \mathrm{H}_{12} \mathrm{O}_{6}\right)$ does not change from extracellular to intracellular so this molecule do not has the major role in its path toward intracellular (the cytoplasm). Then the first case is by assuming that there are no potassium ions inside or outside the cell. Therefore, when glucose with sodium ions entering human's cells their concentrations should be increase systematically. In fact, sodium ions should increase while glucose molecule should not. This because that cell's cytoplasm and mitochondria decrease these molecules by absorbing them continuously and convert them to $\mathrm{CO}_{2}$ gases releasing out of the cell. Then sodium concentration should be increased inside body's cells after each meal of course concentrations balancing between intra-extracellular will remove some of these ions and releasing them out of the cell by kidneys actions. This should decrease these ions concentration from body's cells but even that these ions concentration should be at high levels inside different cells and at low levels outside them. Scientific fact of this status this does not happen because it indicates that sodium ions have too high levels at extracellular and low levels at intracellular $=140: 10 \mathrm{mmole} / \mathrm{L}$ respectively [7].

2. The second case is assuming that there are potassium ions inside different cells but they are not outside. When glucosesodium molecules enter body's cells sodium concentration should increase inside these cells leading to remove potassium ions by $\mathrm{Na}^{+}-\mathrm{K}^{+}$-ATPase pump [7]. Potassium able to enter body's cells again and get out sodium ions $2 \mathrm{~K}^{+}$removed $3 \mathrm{Na}^{+}$ [7]. By repeating this cycle several times with kidney's actions potassium concentration will be not enough lead increasing in glucose concentration than sodium concentration. Therefore a part from glucose molecules should remain in the blood lead to increase them concentration and low concentration of potassium ions in both cases inside-outside body cells. Once again sodium concentration should be more outside than inside body's cells and this is not true because scientific fact indicate that sodium concentration should be higher outside the cell rather than inside as it is mentioned in case of number [1].

3. The third case is similar to what happen in diabetes and hypertension statuses by assuming that low potassium levels are outside the cell and also different body cells have enough potassium ions inside them. The fact of potassium role is to provide glucose's path with sodium ions and keep this path continues supplying with sodium ions. This happens by enter two of them $\left(2 \mathrm{~K}^{+}\right)$into the cell making three sodium ions $\mathrm{Na}^{+}$ get out from the cell and ready to bind with glucose molecules to come back again into the cell. Therefore, in case of low serum potassium amount of sodium ions must stay inside the cell because there nothing can get them out. In addition, potassium ions cannot bind to glucose as sodium ions. Resulting of this high serum glucose levels and low potassium levels outside body's cells [1-4]. These results were found by novel studies [14] that low blood's potassium lead to diabetes and hypertension diseases [1].

These studies are more than good for finding the treatment of diabetes or hypertension because they spent long time with thousands samples, one of them spent about 28 years 1985 to 2013 until they published them researches [2,3], the second one is; Japan's study with thousands samples and about four years [4]. Unfortunately these novel studies did not explain them results and Al-Darraji's study [1] has explained all these results about low serum potassium levels lead to diabetes and hypertension. These studies have introduced a good fact that potassium ion have a major role in diabetes and hypertension diseases. In fact, human's body have certain concentrations from different ions including sodium and potassium so it always needs additional concentrations get them from what it eats or drinks. Human's body cannot stand with continuous decreasing of one of its ions such as important one sodium or potassium.

It is important to clarify mechanism of potassium action into human's body which is; glucose take sodium with it into body's cells so there must be something get out these ions because; Firstly, high concentration of sodium ions inside body cells should increase their pressure on these cells and on them membranes. Secondly, increase sodium concentration inside body cells should prevent another ions from entering these cells means prevent glucose-sodium molecules (diabetes disease). Thirdly, glucose cannot bind with potassium as same as sodium due to its volume comparing with sodium, therefore, potassium ions cannot involve in glucose path. Fourthly, there is a high concentration from each ion inside and outside body cells such as sodium ions at extracellular to intracellular 140:10 mmole/L [7] respectively. This cannot happen without sodium-potassium exchange through cell's membrane. Fifthly, during each day human eat different foods and drink different syrups means there is always high glucose concentration in the blood, this is a fact that glucose concentration is relatively constant. Then human's body needs high concentration from sodium ions continually. This indicates that potassium have additional role it must prepare continues concentration from sodium ions by its cycle inside-outside body cells. Sixthly, human body contain billions cells and all these cells absorb glucose very slowly and systematically according to potassium cycles which producing sodium ions continually, then each decreasing in these cycles should cause unbalancing in concentrations of different ions (diabetes and hypertension disease). Seventhly, human body need continues energy and body cells have continues glucose metabolism and these important continues aspects need continues source from sodium ions therefore potassium ions responsible for these important continues roles...etc. there are another points but these are enough for this research.

As it is mentioned before, this research discuss just facts and this what explained in above points that; Formation of glucosesodium molecules by insulin, there is known ions exchange over cell's membrane $\mathrm{K}+-\mathrm{Na}+$ ATPase and low serum potassium cause diabetes and hypertension [1-7]. These facts together lead to understand glucose path from extracellular to intracellular from $\mathrm{C}_{6} \mathrm{H}_{12} \mathrm{O}_{6}$-to- $\mathrm{C}_{6} \mathrm{H}_{11} \mathrm{O}_{6}$ - Na+-toGlucose-6-phosphate. Understanding of glucose path lead to understand its disorders such as diabetes, hypertension diseases and others. 
Facts of this research are reasonable while others are unacceptable such as; Sodium ion $\mathrm{Na}+$ drag glucose with it when it moves into the cell [7]. How sodium do this?! Sodium is ionic a one atom while glucose is a molecule with 24 atoms! This like small creature drag big one into a heavy liquid (like blood and cytoplasm)! How this happen if there is no known bonds between these material (glucose and sodium)?! It is so obvious that there a known bond between these materials and ionic bond is the most suitable one because ion with molecule like glucose must bind by this bond. Ionic bond between sodium and glucose make them act as a salt easy to move through cell's membrane toward cytoplasm [1].

In fact, diabetes and hypertension patients over the world during long time ago tested many herbs, fruits or honey...etc. just for finding good treatments for these diseases. These natural treatments are so useful and it is important to understand that they are experimental treatments come from testing methods such as; O. basilicum in India, C. verum and different honey types here and over the world, before few years diabetes patients used a type of herbs called it "Jarjer" it is a good treatment for diabetes type 2. So many patients here and around the world used honey as a good treatment for diabetes and hypertension, it is really act as this behave in addition many patients around the world using it as a good treatment.

It is so common here and may be in many societies over the world that hypotension's patients use special syrup contain high concentration from known salt $(\mathrm{NaCl})$ as a good treatment for this disease while hypertension's patients use so sweet food or special syrup contain high concentration from sugar. People here use these two experimentally syrups very widely for long time ago as good treatments for these two diseases. It is a fact that these solutions $(\mathrm{NaCl}$ and sugar solutions) were tested by different people and they found that they are good treatments therefore they widely used for long time ago.

The question is what these solutions did in human's body for being a good experimentally treatments for hypertension and for hypotension?! Sugar contains glucose binding to fructose and salt contain two ions $\mathrm{Na}+$ and $\mathrm{Cl}-$ so which one is the affective molecule or ions!? Fructose convert to glucose in human's body means sugar is just additional glucose adding to patient glucose and also chloride ions do not have any relation to blood's pressure so the active ions in $\mathrm{NaCl}$ is $\mathrm{Na}^{+}$.

Then these experimentally facts indicate that they use additional sodium $(\mathrm{Na}+)$ for hypotension while they use glucose for hypertension. It is clear now that in case of hypotension they use additional sodium ions to bind with glucose to form glucose-sodium molecules while for hypertension they use additional sodium $\mathrm{Na}+$ for forming same molecules.

These experimental facts indicate that in hypertension there are an excess or high concentration from potassium ions in the blood (extracellular) while in hypotension there are an excess from glucose. Overall hypertension and hypotension diseases are due to sodiumpotassium ions as same as diabetes disease. This fact is so clear that both ions effect blood's pressure and this effect may due to atomic volumes of both ions, potassium has higher volume than sodium so an excess from it in the blood causing hypertension while an excess from sodium causing hypotension. For this in normal cases the higher concentration for potassium ions are inside body cells (intracellular) while the higher concentration of sodium ions are outside body's cells $[6,7]$.

In opposite of this situation in different hospitals over the world and in other medical places, the doctors or their co-workers use sodium chloride salt $(\mathrm{NaCl})$, they called it "normal saline" for many cases including hypotension. Experimental tests show that $\mathrm{NaCl}$ increase blood's pressure as it is mentioned before and When medicine use this molecule then it has many important properties such as; it is active, it is a good treatment, it is a result from experimental tests, it is useful for all people, it is more pure molecule...etc. As mentioned before, chloride ions do not have any relation with hypotension, and sodium ions are responsible for increasing of blood pressure.

This fact need more details, why medicine use normal saline for many cases? What the relation between $\mathrm{NaCl}$ with hypotension? If this salt use for hypotension then it can be used for hypertension. Therefore, when more $\mathrm{NaCl}$ increase blood pressure then less of them should decrease this pressure but how this happen? There is a fact about sodium-potassium relation in the blood at outside body's cells. As mentioned before, if 2 potassium ions $\mathrm{K}+$ enter the cell then 3 sodium $\mathrm{Na}+$ should be got out due to $\mathrm{K}+-\mathrm{Na}+$ ATPase [1-7]. Then it is a fact that good amount from potassium ions each day can treat diabetes and hypertension, this fact come from medicine molecule normal saline.

In addition, sodium chloride $(\mathrm{NaCl})$ solution or normal saline use as nutritive solution that used slowly stepwise leading patient's body use sodium ions as much as possible to form glucose-sodium molecules. Moreover, glucose has good concentration in the blood inside each human's body able to participate with insulin in assistance of sodium ions that comes from nutritive solution resulting increase in body's energy that produce from metabolism of glucose inside each cell. Then advantage of nutritive solution is increase body's energy and use glucose molecules in a patient's blood as much as possible to form glucose-sodium molecule that responsible for producing energy.

A conclusion of above fact that there is a relation between sodium's concentration in the blood with blood's pressures. Low concentration from sodium ions in the blood outside human's cells caused hypotension needs additional ions to treated this disorder, and high concentration from these ions in the blood caused hypertension needs two treatments for this disorder; Either using appropriate amount from potassium ions or the better treatment is by using good amount from glucose molecules because sodium ion $\mathrm{Na}+$ drag glucose with it when it moves into the cell [7]. This is what people do by drinking syrups contain high amount from sugar (glucose) for treating hypertension disorder. Therefore, it is possible to increase or decrease blood pressure by controlling sodium's level.

There are a lot of herbs, different syrups and honey that acting as good treatments for diabetes and for hypertension but patients of these diseases are so confused about which one is better? are they really act as good treatments?! This for all patients over the world in addition there are many T.V. programs show benefits of a lot of herbs, fruits or honey that useful as good natural treatments. This research show what this natural product have to be good treatments for diabetes or for hypertension.

The fact of glucose path in human's body from the blood to cell's cytoplasm is done by two main steps; First one is that insulin form glucose-sodium molecule to make it easy moves into different body cells passing through them cells membrane. Second step body's cells are in billions so after consuming all sodium ions by forming of glucose-sodium molecules and after them moving inside different cells, something must get them out. Potassium ions do this step, get sodium ions out from different body cells and prepare enough concentration from them outside body's cells to be ready for another meal.

Results of these steps, high concentration from potassium ions 
should be inside different cells of human's body and high concentration from sodium ions should be outside these cells. This indication is same as the facts of these two ions concentrations inside or outside human's cells [1-7] and this is the healthy situation without diabetes or hypertension. Different herbs, fruits or honey that mentioned in above paragraph contain good amounts from sodium and potassium [6] and results of this research has showed high concentration from these ions in honey and in C. verum.

The fact of all these natural products that they have enough ions from potassium and sodium. For sodium ions they adding to body's sodium ions in the blood and participating in forming of glucosesodium molecule. This means that these additional sodium ions should assist body's ions to form glucose-sodium molecules. For potassium they do what they must do; Getting these sodium ions out of body's cells and keeping blood pressure be in normal status and also prepare enough sodium ions in the blood for another glucose molecules; Potassium ions inside human's cells whereas sodium ions are at outside [1-7].

Then these different herbs, fruits and honey have a good action by providing glucose path with additional necessary ions so they act as a good treatments for diabetes, hypertension and may be for other disorders.

However, these natural product must use many times in each day because there is no final treatments for diabetes or for hypertension. The fact of human's body is that; glucose path is continues processes need continues ions from potassium and sodium. Unfortunately the world's real problem is that commercial water that come from different filters, these waters do not have enough amounts from sodium and potassium and other important ions so human must get what it needs different ions from its foods but human's foods sometimes do have enough amount from important ions.

This fact is well understand that human's foods must provide the body with necessary ions because its water does not have these ions. Human must complete the deficiency of important ions in its different water types from its foods and this is difficult to most people specially older one therefore human specially older people are always under risk of happening of diabetes or hypertension. This is true without any doubts but if human know that important ions are the reasons of these diseases then this become very ordinary for him to treat them so easily.

Potassium and sodium ions have good cycles in human lives since the beginning; the excess from them in human's body should be removed by kidneys to different water sources and to the grounds. Then human get them either from its drinking water or from different foods that come from the ground. These cycles keep different ions between human's body and its around nature without no wastes. Unfortunately different filters that producing commercial water are prevent big ions including potassium and in somehow sodium making the water be less ions specially potassium ions.

It is important to mentioned two points that; Firstly diabetes disease is not a disease like other diseases, it is disorder in different ions concentrations of human body [2-4] so it does not have types either diabetes due to potassium and sodium ions and it can be treated by appropriate amounts from these ions, or it becomes a disease when there is damaging in $\beta$-cells make it difficult to produces insulin. Secondly, there are a lot of cases that children's have diabetes or even it happens to young or to old people. These cases come from that human's or children's bodies do not have enough ions and the shock, eating sugar too much, etc... push them bodies to consume important ions very fast leading to decrease them concentrations in the blood resulting an increase in glucose concentration.

In other words, bodies of these people do not have enough ions and they consume most of them very fast so glucose increase in them bodies. Best treatment for these people is by giving them good amounts from potassium and sodium ions by 2:1 respectively.

Reaction of insulin with glucose is reversible [1] so giving these people injection of insulin must effect forward reactions to be more than backward reactions resulting decrease in glucose concentration but it is not too much and this is not a suitable treatment. It is important to understand when calculating glucose concentration must be calculating insulin concentration as well, if both of them have normal concentration then potassium and sodium is the reason of increasing glucose concentration in the blood. Or there is decreasing in insulin concentration then there is something wrong in $\beta$-cells.

Measuring of serum potassium and sodium ions should be the major analysis for blood's pressure, as mentioned before these ions able to treat diabetes and hypertension.

A conclusion of this research, balancing in different ions concentrations in the blood by eating or drinking enough ions specially potassium and sodium is more than enough for human to be healthy without diabetes or hypertension.

\section{Acknowledgement}

A thanks with respect to my family for all of them and special thanks to my colleagues.

\section{References}

1. Al-Darraji AH (2013) Diabetes, Blood Pressure and relating Diseases; Reasons and Solutions. European J Scientific Res 104: 53-78.

2. Chatterjee R, Yeh HC, Shafi T, Selvin E, Anderson C, et al. (2010) Serum and dietary potassium and risk of incident type 2 diabetes mellitus: The Atherosclerosis Risk in Communities (ARIC) study. Arch Intern Med 170: 1745 1751.

3. Chatterjee R, Yeh HC (2011) Potassium and the Risk for Type 2 DiabetesAfrican-American Study. J Clinical Nutrition.

4. Heianza Y, Hara S, Arase Y, Saito K, Totsuka K, et al. (2011) Low serum potassium levels and risk of type 2 diabetes: the Toranomon Hospital Health Management Center Study 1. Diabetologia 54: 762-766.

5. Seeley RR, Stephens TD, Tate P (2006) Anatomy and Physiology, Seventh Edition, McGraw-Hill companies, China.

6. Personal communication with lecturers in Chemistry and in Biology department/ College of science, 2016-2017.

7. Murray RK, Bender DA (2012) Harper's Illustrated Biochemistry (29thedn), McGraw-Hill companies Inc. 459-477. 